\title{
Media Language: Video practices
}

\author{
Karen Bosy \\ Royal College of Art \\ London, UK \\ karen.bosy@network.rca.ac.uk
}

\author{
Cristina Portugal \\ National Council for Scientific \\ and Technological, Brazil \\ crisportugal@gmail.com
}

\begin{abstract}
This project explores the blog as a context considering the articulations between the context and content (blog and videos) forming this project. In order to do so, hyperlinks to practitioners' videos (uploaded to individual Vimeo accounts), are gathered together on a blog page. Contributors are asked to consider the prompt of a glass of water for a video-based active reflection on their practice. A glass of water is an object of the everyday, yet one often present in interviews; this project started as a series of interviews. The water or the glass can be present or not present in the video, for example materiality could be considered, or perhaps the 'publicness' connected with the water glass at a site of presentation could be explored. Other ways may be found. This is a collaborative work where practitioners survey their individual use of media through the prescribed method of digital video. The result of the work can be accessed on Seminar Project website (http://www.kmbosy.com/blog/seminar-project).
\end{abstract}

Art. Video. Media. Blog.

\section{INTRODUCTION}

The question guiding this work progressed from the reflection that social relations are not only mediated by the oral and written language, but by means of an intricate and plural network of languages. We also communicate by means of the visual language, objects, music, sounds, gestures, expressions, smells and touch, through appearance and feeling. In this study we will discuss questions regarding the media language of a blog as a virtual social space of communication.

Media languages comprehend the set of resources used in information representation, in other words, texts, images, sounds and videos. Consequently, given the correlation of all those elements, multimedia is configured as one of the most effective ways of presenting information, substantially amplifying the understanding of a message. Burdick et al. (2012) widen this idea when talking about the culture of the screen:

Seen culture of Digital Humanities is often dynamic and time based, drawing on a multitude of traditions of media practice. Here, the aesthetics and techniques of video are particularly relevant. (Burdick et al. 2012 p.14)

The objective of this research is to encourage the reflection about the articulations between the multiple means of expression made available by digital media.
The method used for developing this collaborative work progressed from a series of interviews with artists and designers about the subject of media used in a practice. Therefore, it was asked for some artists and designers to produce a video from a specific process as a way of representing their own media. Collaborators use a glass of water, an object from daily life, as the starting point.

This paper presents the reflections of the 'blog' as a virtual space and a depository of videos created by collaborators involved in this project and we present the results of the work developed by the participating practitioners.

\section{THE BLOG AS A VIRTUAL COMMUNICATION SPACE}

The blog as a virtual communication space, defining communication as a symbolic and complex process by which people build their meanings and share information inherent to their ideas, their values and their social practices.

Information and communication technologies allow, by means of hyperlinks, a new grammar of possibilities, a new way of writing and narrating. (Johnson 2001). Queau (1999) found that new rhetoric will develop on the basis of complex combinatorics between differentiated image levels, putting into play different levels of hybridisation between real and virtual, between synthetic and 
natural. Continuous metamorphoses can chain together between those representations.

McLuhan (1964) says about hybridisation:

The hybrid, or meeting of two means, constitutes a moment of truth and revelation, from which the new form is born. This is because the parallel of two media keeps us on the borders between forms that awaken us from narcissistic narcosis. The moment of meeting of two means is a moment of freedom and liberation from the numbness and trance that they impose on our senses (McLuhan 1964, p.75).

With the advent of such technologies, it was possible to create new ways of handling text, images, and audio, in other words languages. According to Queau (1996), the image generated by technologies, taken as ubiquitous writing, should not be seen as natural, absently seen, but it must be read in advance, analysed, compared to its context, as we learn to do it in the information field of writing on static support.

In order to develop the awareness about these changes the blog, as a virtual space, is equivalent to data fields in which each point can be considered as the entry door for a data field, towards a new virtual field, itself leading to other data spaces.

New ways of mental navigation will be needed in order to reconnect in the informational mazes in constant regeneration (Quéau 1996). Burdick et al. (2012) say that currently one needs to be in tune with the sophisticated visual literacy.

Understanding the way one structures the relationships among data, the ways in which users input and access information, and the physical and conceptual design of such systems all-too-often slips away into the abstraction (Burdick et al. 2012, p.19).

Chartier (2001) also reinforces this idea, information and communication technologies are demanding from the contemporary individual the building of singular structures, regarding the comprehension and apprehension of knowledge, saying that: When thinking about what happens in the contemporary world, it becomes very clear that everything we think as stable, invariable or universal, fragments into a discontinuity or in a series of particularities. Thus, an awareness or auto awareness about the singular situation of each one of us has a place in a present that is also singular.

The blog, as virtual space, enables artists and designers, by means of hyperlinks, to link their singular works and to browse in order to see the work of other practitioners, who had the same challenge of creating a video from a glass of water. These reflections about the blog are supported by Burdick et al. (2012):

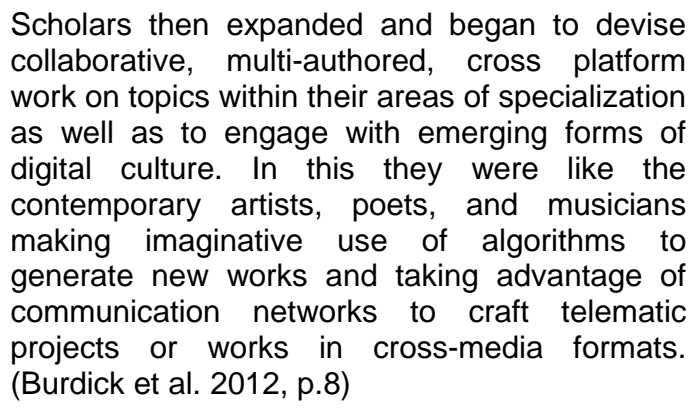

Thus, the blog uses hyperlink functions such as: selecting the area of interest, creating links between those points, connecting the text to other documents, sorting it to a whole memory that makes a kind of a base over which it highlights and to which it refers, so that there are interlinks between the system, the content, the users.

The idea of interconnections of nodes seems to be subjacent to understanding the language of the media as a presentation of information made available by means of a network of nodes interconnected by links, which may be freely accessed by the user in a non-linear way.

On the other hand, the blog, as virtual space, through the internet institutes the possibility of giving a voice to 'all', of searching by alternative paths, of choosing and searching a matter of interest, of having access to exchanges about the most different subjects, of becoming an author, coauthor and transforming the unilateral speech in hyperlink. Manovich (2001) complements this idea saying that:

\footnotetext{
New media is interactive. In contrast to old media where the order of presentation is fixed, the user can now interact with a media object. In the process of interaction, the user can choose which elements to display or which paths to follow, thus generating a unique work (Manovich 2001, p.49).
}

The blog as collaborative space propitiates converging participatory actions allowing the discussion and reflection about the media language that, according to artist Wenger (2009), those spaces generate a collective identity, even if, on the other hand, the individual action brings to the media universe the diversity and multiculturalism, which enriches in a sense of progressive amplitude.

Technologies create new ways of action and social organisation. Technological transformations and their social, ethical, environmental consequences, among others, are processed in a fast pace, 
challenging professionals in their daily practice, and producing an expressive change in the use of writing communication and the new forms of media language.

Browsing through the blog, it is possible to perceive that Ktess (2003) was right to state that there are two distinct factors, however related between them, which deserve to be particularly highlighted. On the one hand is the movement being produced since the writing that, during centuries, dominated our means of communication, for the new domain of the image composed by the movement that goes from the domain of media book, to the domain of media screen. Those two changes are producing, by themselves, a revolution in the uses and effects of visual literacy and associated means to represent and communicate in all levels and scopes.

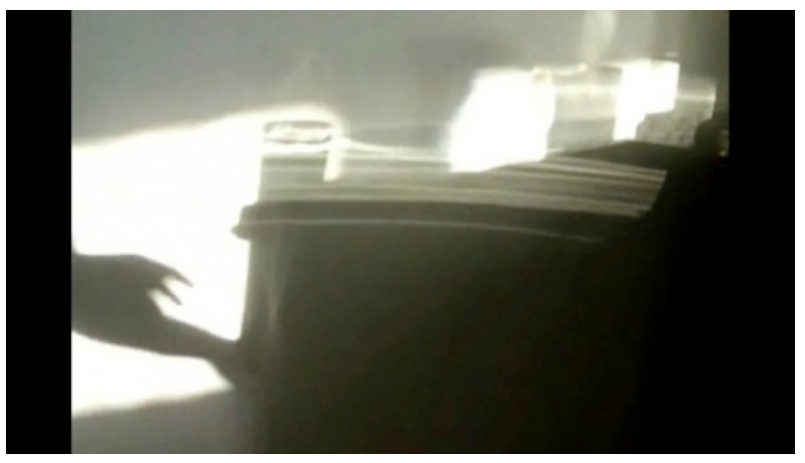

Figure 1: 'Nude with water.' Joanna Roykovska

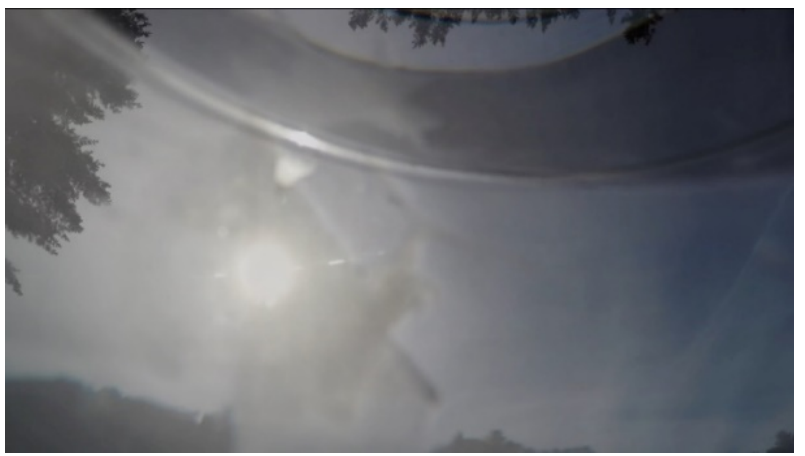

Figure 2: 'Water.' Corinne Duchesne

\section{THE BLOG AS A DIARISTIC SPACE}

This project explores the blog as a context considering the articulations between the context and content (blog and videos) forming this project. In order to do so, hyperlinks to practitioners' videos (uploaded to individual Vimeo accounts), are gathered together on a blog page. Contributors are asked to consider the prompt of a glass of water for a video-based active reflection on their practice. A glass of water is an object of the everyday, yet one often present in interviews; this project started as a series of interviews. The water or the glass can be present or not present in the video, for example materiality could be considered, or perhaps the 'publicness' connected with the water glass at a site of presentation could be explored. Other ways may be found.

The blog as a site for self-expression affords a space for documentarist practices of selfrepresentation and self-examination whilst inflecting these diaristic forms. Practices of selfrepresentation and self-examination are exemplified by the widely disseminated diary of Samuel Pepys. As another example, Benjamin Franklin was an early 'self-tracker', recording and sharing his efforts to improve, as Jill Walker Rettberg observes (2014, p.10). Pepys' diaristic texts were disseminated and Franklin's were selectively shared as the contents of diaries and personal journals were not always intended to be secret and similarities can be found between these forms of diaristic texts and blog sites that are regularly updated or based on a theme (Rettberg 2014). Considering the blog form in diaristic terms fits the manner in which new media replaces old media in Marshall McLuhan's widely accepted notion of remediation (Jensen, p.199, 224). However, diaries and personal journals are not usually published and the inherent 'publicness' of a blog site affords an experience that although diaristic is also discoverable. In this case, considering the blog as a context that is inherently public, digital media's long reach, and the newer (vertical) processes of intertextuality, the experience of a blog site can move between a contained and intimate one on a blog page for example, to one that is unbounded (Jensen 2012). This possible increase in scale, and the possibility of public exposure, even when this is sought, is different to the intimate experience afforded by a diary or journal, even when these texts are disseminated.

This project's videos are contributions from art and design practitioners. These are subjective reflections in video form, on concepts relating to a glass of water. The blog format supports participatory ways of working; the video reflections are gathered together on a blog page using hyperlinks. Considering the blog in relation to a diary or personal journal, these videos take on the role of contents, and gathered together can be understood as diary or journal entries. However the blog page is underpinned by the affordances of the digital space and digital media's long reach (Jensen 2012). Information such as the practitioners' geographical location is not disclosed by the Vimeo accounts, however, text is contributed by the practitioners if wanted and posted on the blog page near each corresponding Vimeo thumbnail. The videos using the traditional languages of art and design, and informed by 
historical and cultural understandings in these fields are anchored by text, and placed in an intimate relationship in the space afforded by the blog page, underpinned by the new languages of this 'context' (Jensen 2012, pp.189-190).

Richard Serra's film Hand Catching Lead (1968), exemplifies an active reflection on a specific concern within an art practice. Serra, an artist with a long practice exploring site using site-specific sculpture, made Hand Catching Lead (1968), to explain his installation House of Cards (1968). Serra (2018) explains that in this installation 'you either get the equilibrium right or you don't' as panels of lead are propped together to demarcate a space, foregrounding weight and gravity (p.34). In this film of a hand struggling to stay within the frame of the camera in order to catch pieces of lead falling through the frame, and in his site-specific practice and early films, Serra interrogates the frame and its limitations in denoting a space (pp.75-77). To do so he draws on the traditional language of structuralism using a fixed camera position, that is, 'fixed from the viewer's perspective', and as Catherine Russell explains this structuralist aspect 'imposes a frame onto reality' limiting a view to 'inside and outside'. The fixed frame points to the subject and also to the 'four sides of the frame beyond which is the continuity of the real, as defined by the discontinuity of the frame' (p.158).

When the blog is considered as a context that in some ways also corresponds to a frame (Jensen 2012, p.195), it seems possible to draw on the language of structuralism in this project as Serra has done in his films. In structuralism a frame can denote a space (a generative gap) between the video images and the viewer, as Catherine Russell (1999) explains. In addition the video thumbnails and the text contributed by each practitioner foreground the surface of the image denoting a space, another structuralist technique. The videos when viewed using the thumbnails, also benefit from the process of anchorage and relay as explained by Roland Barthes (1977). In a similar way to an artwork's title, the text anchors the videos to meaning, and through the process of relay operating 'on differences'; meaning is understood through text and images being put together at a 'higher level'. As Jensen continuing observes, relay is a 'key issue' in 'trying to account for the heterogeneity' of digital media since the 1980s (Jensen 2012, p.151). In this case, digital media's long reach still needs to be taken into account as a part of the frame afforded by the blog; the videos are not actually placed in the blog but in various Vimeo accounts and gathered together using hyperlinks.
Facilitating hyperlinks is one way the blog as a context supports the (dual aspect) process of intertextuallity (Kristeva 1984). As Jensen (2012) explains, drawing on Fiske (1987), the traditional languages of art and design are part of the horizontal aspect of this process while the blog also supports the new, shorter term languages of mass media, a vertical dimension which 'includes the audience' as a media (pp.191-192). Viewing the videos a different way by using the new language of this context or frame, and, for example using a hyperlink to leave the blog to access a video in the Vimeo website, increases project's scale and reveals the blog as inherently public. In this way of viewing the Vimeo website, other websites, blogs, videos, texts, sites and viewers are included in the experience of the video reflections.

Viewing video(s) and connecting space(s) this way is explored by practitioners. For example, for artist and filmmaker Laure Prouvost a semi-narrative text with embedded hyperlinks fulfils the function of a website menu. The increase in scale afforded by digital contexts, for example the blog, can be controlled in some ways, for example by requiring a password to a Vimeo account as Prouvost has done. Using passwords to control access can increase the privacy of a blog site adding intimacy through a selection process and bringing the experience in some ways closer to a disseminated diary. However, the tension between the intimate space of the blog page and the inherently public and larger scale (vertical) aspect of the context (the blog) is in part the experience afforded by the blog and found in this project. As an example, when viewing the contents of the videos when using thumbnails, once a video is played it is replaced with a Vimeo screen offering three hyperlinked screen shots of Vimeo's 'Staff Picks' videos; Vimeo's 'Staff Picks' videos are a selection of videos that are not contributed by practitioners to this project. As each contributed video is played it is replaced by this hyperlinked Vimeo now included in the process of anchorage and relay (as explained by Barthes). The Vimeo screen is not a part of this project's regular up-dates and the videos offered are not within the theme of the project. However Vimeo's 'Staff Picks' remain in view unless the viewer actively clicks away through using 'replay' to return to the contributed video or until the blog is refreshed. In this way Vimeo transgresses the intimate space of the blog page placing other hyperlinks within the space of the project, and includes the inherently public and unbounded aspect of the context (the blog) in the experience afforded by the blog and found in this project. The diaristic experience of this project although in some ways similar to that of a diary, is not the intimate as inherently private and bounded experience afforded by a diary or journal, even when these texts are disseminated. 


\section{PARTICIPATING PRACTITIONERS}

The following provides a list of video works by the participating practitioners. See Figures 3-7 for still images from these.

- Alram, F., Portugal, C., Bosy, T. 'Ephemeral.' Vimeo. Accessed March 3, 2019. https://vimeo.com/288579211.

- Bosy, K. 'Private.' Vimeo. Accessed March 3, 2019. https://vimeo.com/295435678.

- Duchesne, C. 'WATER.' Vimeo. Accessed March 3 , 2019. https://vimeo.com/309027627.

- Fahey, O. 'Shared Space.' Vimeo. Accessed March 10, 2020. https://vimeo.com/391823337.

- Gipp, G. \& Harris, S. 'Mission from 'Arry.' Vimeo. Accessed March 17, 2020. https://vimeo.com/398199875

- Jones, C. 'The Magic System at Work in a Developing Nation: Bonafont Day 1 LEGEND' and 'The Magic System at Work in a Developing Nation: Bonafont Maralyn'. Vimeo. Accessed July 14, 2019. https://vimeo.com/346962505,

https://vimeo.com/346961342.

- Loughlin, I. 'Performance with a Mirror for Trees_Irene Loughlin.' Vimeo. Accessed March 3019. https://vimeo.com/320085568.

- Martin Ganzinotti, M. 'Traces.' Vimeo. Accessed March 12, 2019. https://vimeo.com/321858649.

- Moody, P. 'A Glass of Frozen Water Begins to Thaw',

2019.

https://vimeo.com/325215353.

- Oskay, C. 'Cup of Water on Hyde Park', Vimeo. Accessed July 16, 2019. https://vimeo.com/348400352.

- Poon, D. 'Waiting By Water.' Vimeo. Accessed March 3, 2019. https://vimeo.com/304246586.

- Portugal, C., Bosy, T., Alram, F., 'Nature.' Vimeo. Accessed March 19, 2019. https://vimeo.com/325255933.

- Roykovska, J. 'Nude with Water.' Vimeo. Accessed March 3, 2019. https://vimeo.com/106498159.

- Roykovska, J. 'Water2 S.' Vimeo. Accessed March 3 , 2019. https://vimeo.com/186015357.

- Roykovska, J. 'Spiral.' Vimeo. Accessed March 3 , 2019. https://vimeo.com/112388382.

- Spanou, K. 'Possible Landscapes', Vimeo. 2016. https://vimeo.com/168541728

- Van Bork, F. 'C_G Movie', Vimeo. Accessed March 3, 2019 https://vimeo.com/310846838

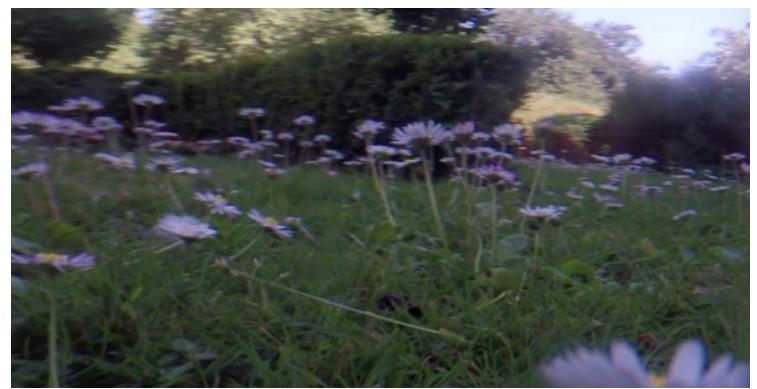

Figure 3: 'Nature' Cristina Portugal

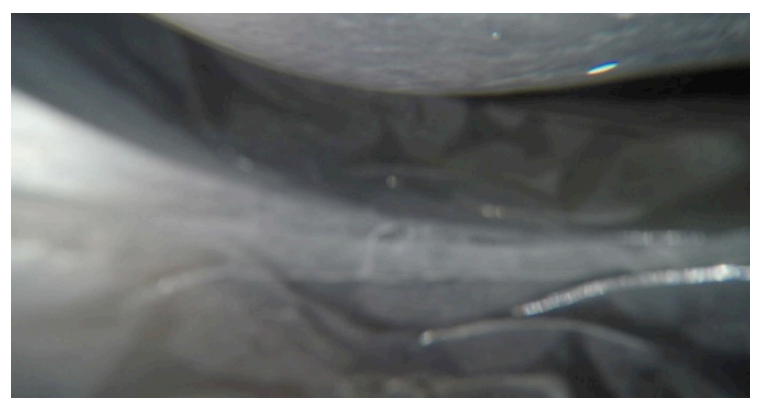

Figure 4: 'Private' Karen Bosy

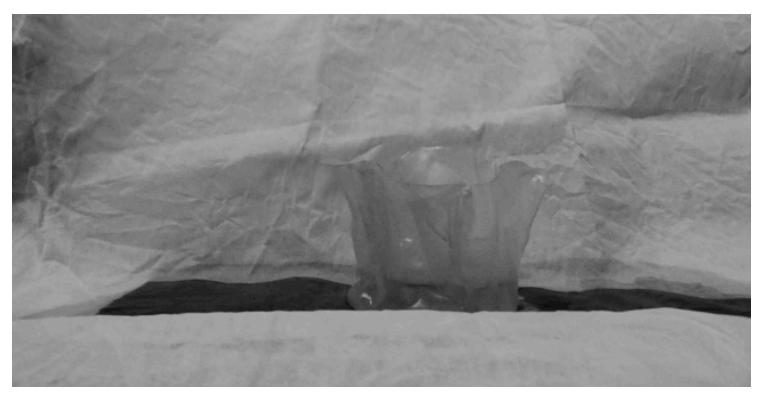

Figure 5: 'Waiting by Water' Debbie Poon

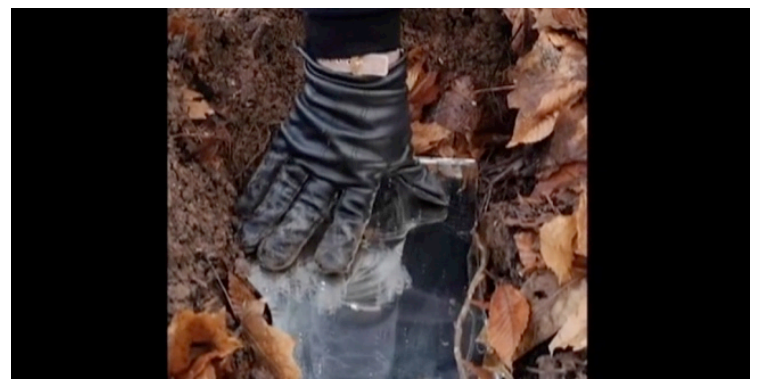

Figure 6: 'Performance with mirror for Trees' Irene Loughlin

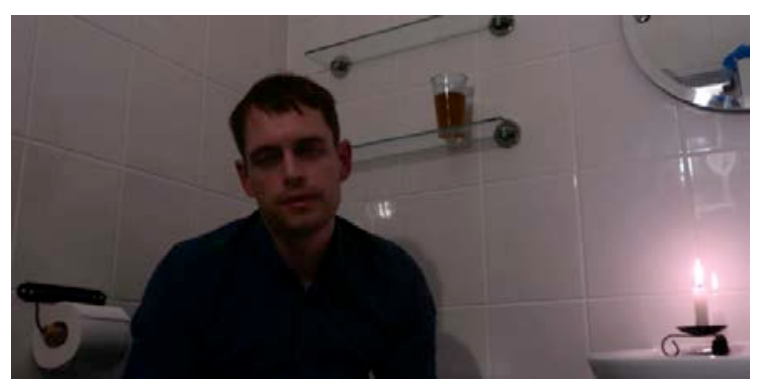

Figure 7: 'Mission from 'Arry' Gipp, G. \& Harris, S. 


\section{CONCLUSION}

This project explores the blog as a context considering the articulations between the context and content (blog and videos) forming this project. Each hyperlink connects the blog to a contributor's video within a Vimeo account. Viewing the videos connects space(s) in a relational way; relationality is inherent to communication (Jensen 2012, p.190). By facilitating the use of hyperlinks in this project, the blog as a context frames the Vimeo site, another context. Considering again the way in which the fixed frame in structuralism denotes a space, although the blog as a context corresponds in some ways to a frame and can seem fixed, the blog facilitates an increase in scale. Using the hyperlinks increases the scale of this project as viewers link physical sites, virtual social spaces and websites when accessing the blog and using the hyperlinks.

There is a tension between the diaristic, intimate space of the blog page and the context (blog) as a frame facilitating an increase in scale, and this experience is not the experience afforded by a diary or personal journal. Although videos contributed by art and design practitioners using traditional languages take on the role of contents, and gathered together can be understood as diary or journal entries, the blog also supports the new, shorter term languages of mass media, which includes the viewer as media, within the processes of intertextuality (Kristeva 1984), anchorage and relay (Barthes 1977). As an example, the viewer can respond by clicking on a video that is not included in the project such as one offered by Vimeo's hyperlinked 'Staff Picks' screen. This exposes the inherently unbounded aspect of the blog, transgressing the intimate experience of the project. The seemingly intimate as bounded experience of the diaristic blog page in this project is inflected by the blog as a context whether or not the viewer uses the hyperlink to access another site.

\section{ACKNOWLEDGMENT}

CNPq - National Council for Scientific and Technological Development from Brazil, Bolsista de Produtividade de Pesquisa (PQ) - Proc. $\mathrm{N}^{\circ}$. 7547547039015568. To School of Communication, RCA.

\section{REFERENCES}

Barthes R. (1977) Image, Music, Text. London: Fontana Press.

Bosy, K. (2018) 'Seminar Project' kmbosy.com [blog]. http://www.kmbosy.com/blog/artworkseries/seminar-series/ (retrieved 5 March 2020).

Bosy, K. and Portugal, C. (2019) Signs of Expression. São Paulo: Infodesign, 16(3), p.349359.

Burdick, A., Drucker, J., Lunenfield, P., Presner, T. and Schnapp, J. (2012) Digital_Humanities. Cambridge, MA: MIT Press.

Chartier, R. (2001) Cultura Escrita, Literatura e História. Porto Alegre. Armed.

Jensen, K. B. (ed.) (2012) The Handbook of Media and Communication Research: Qualitative and quantitative methodologies. 2nd ed. New York: Routledge.

Jonson, C. (2012) A Dieta da Informação: Uma defesa do consumo consciente. Editora Novatec. São Paulo.

Kress, G. (2005) El alfabetismo en la era de de los nuevos medios de comunicación. Archidona, Málaga: Aljibe.

Kristeva, J. (1984) Revolution in Poetic Language. New York: Columbia University Press.

Manovich, L. (2001) The Language of New Media. Cambridge, MA: MIT Press.

McLuhan, M. (1966/1964) Understanding Media: The Extensions of Man. New York: McGraw-Hill.

Portugal, C. (2013) Design, educação e tecnologia: Rio de Janeiro: Rio Books.

Portugal, C. (2019) DXTDIGITAL. http://dxtdigital.com.br/dxt/index.html (retrieved 12 March 2020).

Prouvost, L. (n.d.) website. http://www.laureprouvost.com/menu.html (retrieved 5 March 2020).

Qéau. P. (2001) O tempo do Virtual. In: PARENTE, André. Imagem Máquina. São Paulo. 34.

Rettberg, J. W. (2014) Seeing Ourselves Through Technology: How We Use Selfies, Blogs and Wearable Devices to See and Shape Ourselves. New York: Palgrave Macmillan (Palgrave pivot).

Russell, C. (1999) Experimental Ethnography. Durham, NC: Duke University Press.

Serra, R. and Foster, H. (2018) Conversations About Sculpture. New Haven: Yale University Press.

Wenger, E., White, N., and Smith, J. (2009) Digital Habitats: Stewarding Technology for Communities. Portland: CPsquare. 